\title{
The Covid-19 Lockdown, Ethics, and Screening
}

\author{
Emeric P. Frohlich* \\ Sunninghill Hospital, Sandton, PO Box 349, Gallo Manor 2052, South Africa
}

*Corresponding author: Dr. Emeric P. Frohlich, Sunninghill Hospital, Sandton, PO Box 349, Gallo Manor 2052, South Africa; Tel: (011) 234 3280-234 3281; Fax: (011) 234 3282; Email: drfrohlich@yourbaby.info

Received: May 24, 2020; Accepted: June 04, 2020; Published: June 24, 2020

\section{Covid-19}

The Spanish flu, SARS, and MERS are corona virus pandemics (1). For the first time in history, however, the information technology allowed us to receive large amounts of instant data regarding the impact of this upper respiratory tract infection. The spread of this new virus, the effects on vulnerable people and our unpreparedness to manage a pandemic in a socially and ethically equitable manner has shocked the free world. TB, Malaria, HIV, or childbirth, to mention only some of the devastating conditions which kill hundreds of thousands of people yearly, mainly in third world countries, do not receive such instant and intense coverage. The knee-jerk response of the politicians and of the authorities to overcrowded, understaffed, ill equipped and unprepared healthcare facilities, combined with raised public expectations, was unprecedented. They were worried about accusations of negligence, their political survival, and feared litigation. Their actions and response were a reaction to the realisation that the largest, strongest, and wealthiest economies were unprepared to receive and treat large numbers of severe causalities, for an extended period. For too long, authorities relied heavily on brain drain, underpaid, privatised and short funded healthcare. They promoted, however, democratic principle of equality, freedom, and choice. This pandemic unmasked the ill prepared, inadequate, insufficient, and unequal healthcare systems. These levels of excellence were not achieved in third world countries where healthcare is not universal, accessible, or functional. Advising, recommending, isolating, quarantining, protecting the old, the sick and the ones at risk would have been democratic and more effective. Building and equipping hospitals, employing more staff, and supplying PPE would have achieved the same results, more cost effectively and without the devastating effect on economy and the instillation of fear in the public. An undemocratic regime's, massive lockdown, suppressed reporting and the great success prompted nationwide lockdowns and limitations of civil rights in major democracies. We sheepishly followed into lockdown. The most unreal rules were invented, implemented, and enforced by authorities. Freedom of choice, civil liberties and rights were brutally curtailed in the name of flattening a curve. This is political and media run management of a pandemic, a scary infodemic. Third world countries have followed democracies and implemented unconstitutional, undemocratic, unethical, immoral, and devastating lockdowns on their population. No science or words can explain the reasoning behind such dictatorial steps, except the poor state and ill preparedness of health services. Should the authorities have had a plan and used the lockdown to build hospitals, manufacture needed quality equipment, high quality PPE, and, enlarge stronger and safer emergency response capabilities, we would be in a better position to restart the world. Hygiene, Social distancing, and facecloths only slow down and prolong, do not avoid, or treat the pandemic. Only primary prevention and effective treatments can control a viral pandemic. Developing strong, specialised, well equipped, expandable, and rapidly deployable emergency healthcare systems, training more specialist and research staff, discovering effective antibiotics, antivirals, vaccines, and vaccine producing $\mathrm{R} \& \mathrm{D}$ should be the priority. This should be the duty of the state, the army or civil defence force who are rather developing better mass destruction capabilities. The annual flu kills half a million, mostly vulnerable people. Millions of new-borns, neonates and under 1-year old children die yearly and the majority could be prevented by implementing simple hygienic, proven effective primary and secondary preventative measures, disinfectants, clean water, and an antibiotic, but we do not have funds. So far, we did not reach the number of fatalities expected with an annual flu epidemic, but we are sacrificing the quality of life, wellbeing and livelihood of billions of people, with a Popular Science style, media driven, political management [1].

\section{Ethically}

1. The autonomy of the people was crushed. Decisions taken were with coercion and coaxing and were not based on a benefit risk analysis.

2. There is no justice in lockdowns for the old, the frail, the sick, the obese or the diabetic. The speed of the spread was slowed down but the risk of contracting the illness and of succumbing to it at a later stage, without an effective antiviral or a vaccine stayed the same. For the majority, the young, the fit and the healthy, the financial losses were enormous. In the third world, the distribution of scarce resources towards an exercise in dictatorial rules conflicting with established legislation was senseless. In the first world, at least governments released trillions of US\$ to support businesses and unemployment. The third world is not coping with the repayment of the interest on borrowed money. We are releasing low risk criminals and arrest joggers, or people traveling to visit family or friends.

3. Are there any benefits from flattening the curve to those at risk? Again, in the absence of a cure or a primary preventative vaccine, it is a frustrating prolongation of the inevitable. 
4. Finally, non-maleficence requires that the interventions, in this case the lockdown and closing of businesses, should not harm society. These actions did irreparable damage to most people, to employment, personal wealth, and the economy.

Restarting economies without treatment or a vaccine, after we frightened the public with this infodemic will be a difficult task. Parents, teachers, experts, opinion makers, the media, the trade unions and politicians advise, warn, blame, and worry about whose fault will it be if a child or a worker will contract the disease, or will succumb to it. The blame game has no limits, but government's coffers has. Unemployment and poverty can only make this depression and the future bleaker. After this flu epidemic the media claims that life will not be the same, the question is why and at what cost.

\section{Screening}

For antigen or antibody is another thorny issue. Scientists have adopted the 1968, Wilson and Jugner [2] principles of scientific screening for disease. Screening is not a diagnostic test and it should be applied to a condition, based on sound scientific grounds. The condition should be an important health problem. It should have a known natural history and early diagnosis should have a benefit to the person and the society. Preventative strategies or early treatment should be better than the natural course of the disease or diagnosis and treatment at later stages of the disease. Screening should be effective and outweigh any potential harm to an otherwise healthy population. The test should be reliable, sensitive, and specific. The screening should be acceptable to the population. We should have a policy on management of positive tests, have a diagnostic test, a treatment, and facilities for managing positive individuals. A costbenefit analysis should be performed to balance case funding in relation to general medical expenditure, and the screening should be a continuous process rather than once-off. In 2018 Dobrow [3] expanded on the 10 principles with a rather extensive systemic review and consensus. The screening performed worldwide, by the media, governments and opinion makers is costly, inefficient and unscientific. Besides the relative seriousness of this upper respiratory infection, contagion, acceptability, and ease of screening, none of the requirements for scientific screening or testing are fulfilled. Screening, without guidelines, without knowing the natural history of the condition, without tested and validated kits, without a sensitive and specific diagnostic test for infection or immunity, without facilities to deal with the infected persons and without treatment or a vaccine, is an expensive and futile repetitive process.

\section{References}

1. Jones DS (2020) History in a Crisis-Lessons for Covid-19. N Engl J Med 382: 16811683. [crossref]

2. Wilson JMG and Jugner G (1968) Principles and practice of screening for disease Geneva, Switzerland, WHO, Report No 34 (Public Health Papers).

3. Dobrow MJ, Hagens V, Chafe R, Sullivan T, Robeneck L (2018) Consolidated principles of screening based on a systematic review and consensus review. CMAJ 190: 422-429. [crossref]

\section{Citation:}

